\title{
FISH ANTIFREEZE PROTEINS AND THE CREEP OF POLYCRYSTALLINE ICE
}

\author{
By John W. Glen and David J. IVES
}

(Department of Physics, University of Birmingham, Birmingham B15 2TT, England)

ABSTRACT. Creep curves obtained from the polycrystalline ice samples containing low concentrations of antifreeze glycopeptides (AFGPs) do not show the re-accelerating or tertiary creep that is found in pure ice samples. Previous work has shown that AFGPs inhibit grain-boundary migration in ice and the present results are consistent with this, as tertiary creep is associated with nucleation and growth of new ice grains.

IT has been reported (Knight and others, 1984, 1988) that the antifreeze glycopeptides (AFGPs) which protect Antarctic fish from freezing also inhibit recrystallization and grainboundary migration in ice, even at concentrations as low as $10^{-7} \mathrm{~g} \mathrm{~g}^{-1}\left(\mathrm{c}\right.$. $\left.10^{-10} \mathrm{M}\right)$. Recrystallization is involved in the creep of polycrystalline ice and the process of creep may therefore be influenced by the presence of AFGPs. Single ice crystals deform easily by slip on the basal (0001) plane; a polycrystalline aggregate cannot deform using only this easy-glide mechanism but needs a further process such as grain-boundary migration or recrystallization. Thus, unlike single crystals, polycrystalline ice initially has a creep rate which decreases with time as deformation of those grains oriented for slip under the applied stress is inhibited by the effect of other grains oriented so that the shear stress on the slip plane is small. This is the explanation given for the initial decelerating or transient component of the typical creep curve of polycrystalline ice. It is followed by a secondary, or steady creep attributed to some recovery mechanism and at larger strains, by an accelerating or tertiary creep associated with the dynamic recrystallization of the ice. This is the explanation given (Glen, 1955) for the typical creep curve of polycrystalline ice. Thus, if AFGPs inhibit recrystallization, they should also suppress the tertiary creep and perhaps slow down the earlier stages if significant grain-boundary migration is involved in them. This short note reports the first tests to investigate this phenomenon.

The proteins used were a mixture of AFGPs 1-5 isolated from Antarctic fish by A.L. DeVries. Cylindrical specimens of randomly oriented polycrystalline ice with and without the AFGPs were prepared by first loosely filling moulds with frost particles from the cold-room cooling tubes. The moulds were then filled with ice-cold water (with or without the additive) and then frozen at $c$. $-15^{\circ} \mathrm{C}$. The AFGP solutions used had a concentration of $c$. $10^{-7} \mathrm{~g} \mathrm{~g}^{-1}$.

The creep-testing machine used was similar to that used by Homer and Glen (1978). The stress was supplied by weights and the strain was measured using a displacement transducer. The creep tests were all performed at $-1.5^{\circ} \mathrm{C}$. Three stress levels were used: 570,860 , and $1210 \mathrm{kPa}$. The resultant creep curves are plotted in Figure 1 in the form of strain-rate plotted logarithmically against strain. In this plot the transient primary creep is represented by the descending curve on the left of the plot. Continuing steady-state creep gives a horizontal line, while tertiary creep gives a rising curve on the right. In no case did a specimen containing the antifreeze protein show tertiary creep. In all pure ice samples, a minimum creep rate was reached at about the same strain $(2.5-3 \%)$ and was followed by a rising, tertiary, creep rate. For a given stress and strain, the strain-rates of the samples containing AFGPs were significantly less even during primary creep.

Since it is known (Glen, 1955; Gow and Sheehy, 1987) that pure ice recrystallizes both during deformation and after deformation has ceased, and since this recrystallization

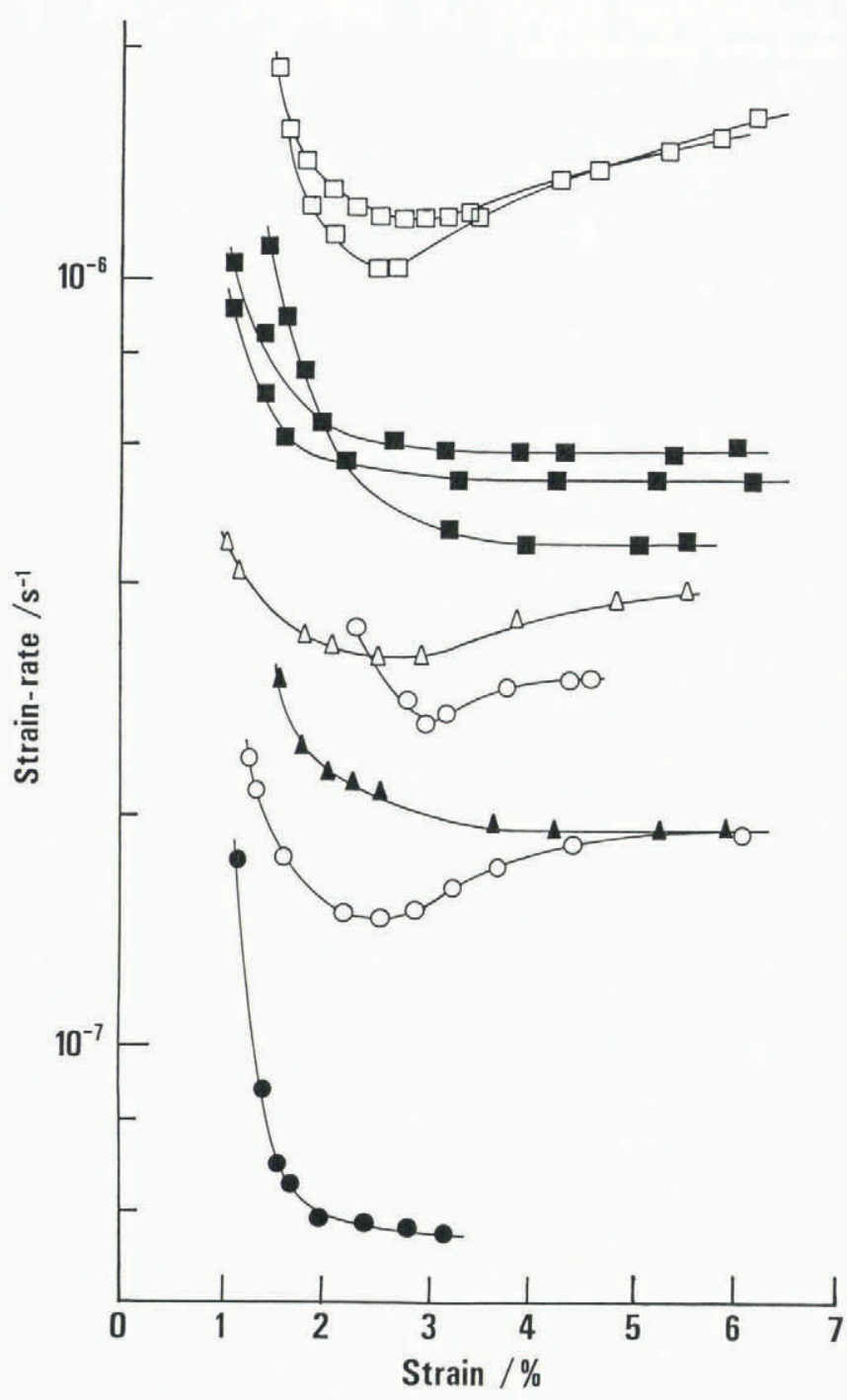

Fig. 1. Strain-rate of polycrystalline ice plotted against strain in constant-load creep tests at $-1.5^{\circ} \mathrm{C} . \square 1210 \mathrm{kPa}$, without AFGPs; $1210 \mathrm{kPa}$, with AFGPs; $\triangle 860 \mathrm{kPa}$. without AFGPs; $\triangle 860 \mathrm{kPa}$, with AFGPs; O $570 \mathrm{kPa}$, without AFGPs; - $570 \mathrm{kPa}$, with AFGPs. Only selected points are plotted. Note that all the specimens with AFGPS settle to a steady secondary creep rate with no indication of the acceleration which is seen in all the undoped specimens. 
produces new grains with an orientation fabric more favourably oriented for deformation, it has been suggested (Glen, 1955; Gao and Jacka, 1987) that the tertiary acceleration is due to this recrystallization. The present experiments are consistent with this view since the specimens containing AFGPs, which have previously been shown to have their recrystallization inhibited, have now been shown not to exhibit the tertiary acceleration.

Clearly, it would be desirable to confirm this conclusion by appropriate studies on the grain-size of specimens before and after testing, and it is hoped to undertake such tests in the future. The mechanism by which AFGPs prevent grain-boundary motion is not entirely clear. It is probably related to the similar inhibition effect it has on crystal growth, a property of more significance for the Antarctic fish (DeVries, 1984). It is not due to concentration of all the AFGPs at grain boundaries, since Gross and others (1987) have shown that AFGPs are the most highly soluble of all known impurities in ice; however, any concentration imbalance between the bulk ice and the grain boundary could retard boundary migration. The problem of how the AFGPs inhibit growth of ice crystals from the melt has been investigated by Wilson and DeVries (1987); a preliminary report of the present work was made as a comment on that paper and is printed at the end of its abstract.

We should like to thank Dr C.A. Knight for drawing to our attention the possibility of an effect on mechanical properties, and Professor A.L. DeVries for supplying the antifreeze glycopeptides.

\section{REFERENCES}

DeVries, A.L. 1984. Role of glycopeptides and peptides inhibition of crystallization of water in polar fishes. Philos. Trans. R. Soc. London, Ser. B, 304(1121), 575-588.

Gao, X.Q. and T.H. Jacka. 1987. The approach to similar tertiary creep rates for Antarctic core ice and laboratory prepared ice. J. Phys. (Paris), 48, Colloq. C1, 289-295. (Supplément au 3.)

Glen, J.W. 1955. The creep of polycrystalline ice. Proc. $R$. Soc. London, Ser. A, 228(1175), 519-538.

Gow, A.J. and W. Sheehy. 1987. Annealing recrystallization in laboratory and naturally deformed ice. J. Phys. (Paris), 48, Colloq. C1, 271-275. (Supplément au 3.)

Gross, G.W., A. Gutjahr, and K. Caylor. 1987. Recent experimental work on solute redistribution at the ice/water interface. Implications for electrical properties and interface processes. J. Phys. (Paris), 48, Colloq. C1, 527-532. (Supplément au 3.)

Homer, D.R. and J.W. Glen. 1978. The creep activation energies of ice. J. Glaciol., 21(85), 429-444.

Knight, C.A., A.L. DeVries, and L.D. Oolman. 1984. Fish antifreeze protein and the freezing and recrystallization of ice. Nature, 308(5956), 295-296.

Knight, C.A., J. Hallett, and A.L. DeVries. 1988. Solute effects on ice recrystallization: an assessment technique. Cryobiology, 25(1), 55-60.

Wilson, P.W. and A.L. DeVries. 1987. Fish glycopeptide and peptide antifreezes: their interaction with ice and water. J. Phys. (Paris), 48, Colloq. C1, 673. (Supplément au 3.) 